\title{
Extramedullary manifestations of multiple myeloma in the thyroid gland and in the lungs: excellent response to therapy
}

\author{
Fabia Weisser • Christiane Reuter • Christian Taverna
}

Received: 27 February 2010 / Accepted: 16 March 2010 /Published online: 10 April 2010

(C) The Author(s) 2010. This article is published with open access at Springerlink.com

Dear Editor,

A 74-year-old woman was diagnosed with multiple myeloma type $\operatorname{IgG}$ kappa, Salmon and Durie stage III A in August 2004. Haemoglobin was $108 \mathrm{~g} / \mathrm{l}, \mathrm{IgG} 90.3 \mathrm{~g} / \mathrm{l}$, and calcium was normal. Bone marrow infiltration was 40 $50 \%$. She received chemotherapy with cyclophosphamide and prednisone from September 04 to July 05 and reached a partial remission. Upon progression in February 06, she was treated with high-dose dexamethasone until July 06 and had another partial remission. From June 07 to October 07, she was treated with bortezomib and dexamethasone which resulted in a near complete remission. In June 08, CT scan revealed enlargement of the right thyroid lobe $(8.6 \times$ $5.3 \mathrm{~cm}$ ). Cytology showed plasma cells, compatible with extramedullary myeloma. $\operatorname{IgG}$ remained normal. She received radiotherapy to the right cervical region (50 Gy). During radiotherapy, M-protein was increasing. CT scan performed 2 weeks after the end of radiotherapy showed an unchanged right thyroid lobe. Four weeks later, thalidomide and dexamethasone were started. After three cycles, a serological and morphological complete remission was obtained. Treatment was stopped in December 08. In

F. Weisser $(\bowtie) \cdot$ C. Taverna

Department of Internal Medicine, Medical Oncology,

Kantonsspital Münsterlingen,

Postfach,

CH- 8596 Münsterlingen, Switzerland

e-mail: fabia.weisser@stgag.ch

C. Reuter

Department of Radiology, Radiation Oncology,

Kantonsspital Münsterlingen,

Postfach, CH- 8596 Münsterlingen, Switzerland
March 09, a small monoclonal peak in the serum protein electrophoresis was detected. In May 09, CT scan performed because of persistent cough with minor haemoptysis revealed a large mediastinal mass $(6.4 \times 5.1 \times 4.0 \mathrm{~cm})$. Bronchial biopsy showed plasma cells infiltrating the mucosa compatible with extramedullary myeloma. Lenalidomide, high-dose dexamethasone and radiotherapy to the mediastinum (30 Gy) were started concomitantly and resulted in another complete remission (Fig. 1). Therapy with lenalidomide and low-dose dexamethasone is currently ongoing.

Extramedullary (EM) manifestations of multiple myeloma can occur at primary diagnosis, during the disease or as solitary EM plasmocytoma without bone marrow involvement [1]. A longitudinal study on extramedullary disease on 1,003 consecutive myeloma patients showed a rising incidence of EM in the last decades, from $4 \%$ in the period 1971-93 to 12\% between 2000 and 2007 [2]. This trend has been attributed to more sensitive imaging techniques and prolonged patients' survival. There is no correlation between high-dose chemotherapy or the use of novel agents and the increased incidence of EM disease [2]. EM manifestations of multiple myeloma indicate poor prognosis [3]. Patients with EM disease during follow-up had lower levels of serum M-protein and haemoglobin and increased lactate dehydrogenase (LDH), compared to patients with EM disease at diagnosis [2]. Our patient had, at both EM relapses, normal haemoglobin and LDH; M-protein was low.

EM myeloma is frequently treated with radiotherapy despite its role is not well defined in this setting. Forty-four percent of patients with EM disease during follow-up received radiation therapy [2]. There is no consensus on the effect of thalidomide on extramedullary manifestations 
Fig. 1 CT-scans before and after therapy (see text)
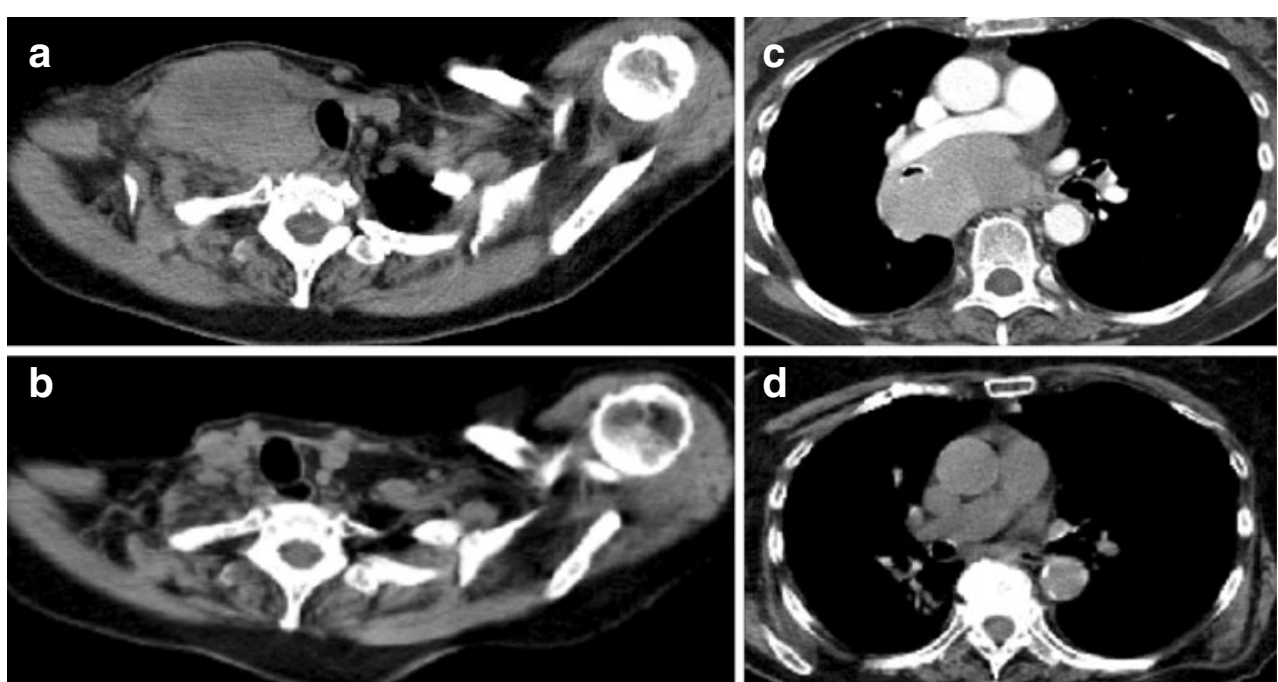

\section{A:CT Thyroid 6.6.2008 B:CT Thyroid 20.11.2009}

C: CT Thorax

7.5.2009

D: CT Thorax 20.11.2009 of MM [4-6]. Reports indicate low response rates of EM disease to thalidomide. Our patient had recurrent EM relapses at two different rarely involved sites, she showed excellent responses to both currently available IMiDs and has long survival of 21 months after first EM relapse. This is in contrast to a recently reported patient with extramedullary disease in the thyroid and the pericardium at presentation who did not respond to any treatment [7].

Open Access This article is distributed under the terms of the Creative Commons Attribution Noncommercial License which permits any noncommercial use, distribution, and reproduction in any medium, provided the original author(s) and source are credited.

\section{References}

1. The International Myeloma Working Group (2003) Criteria for the classification of monoclonal gammopathies, multiple myeloma and related disorders: a report of the International Myeloma Working Group. Br J Haematol 121(5):749-757
2. Varettoni M, Corso A, Pica S et al (2010) Incidence, presenting features and outcome of extramedullary disease in multiple myeloma: a longitudinal study on 1003 consecutive patients. Ann Oncol 21:325-330

3. Cerny J, Fadare O, Hutchinson L, Wang SA (2008) Clinicopathological features of extramedullary recurrence/relapse of multiple myeloma. Eur J Haematol 81(1):65-69

4. Biagi JJ, Mileshkin L, Grigg AP (2001) Efficacy of thalidomide therapy for extramedullary relapse of myeloma following allogeneic transplantation. Bone Marrow Transplant 28:11451150

5. Rosinol L, Cibeira MT, Bladé J et al (2004) Extramedullary multiple myeloma escapes the effect of thalidomide. Haematologica 89(7):832-836

6. Nakazato T, Suzuki K, Mihara A, Kakimoto T (2009) Refractory plasmablastic type myeloma with multiple extramedullary plasmocytomas and massive myelomatous effusion: remarkable response with a combination of thalidomide and dexamethasone. Intern Med 48(20):1827-1832, Epub Oct 15

7. Serefhanoglu S, Sayinalp N, Haznedaroglu IC, Goker H, Cetiner D, Aksu S, Buyukasik Y, Ozcebe OI (2008) Extramedullary plasmacytomas of the thyroid and pericardium as initial presentation of multiple myeloma. Ann Hematol 87(10):853-854, Epub 2008 Apr 12 